\title{
HISTORIOGRAFÍA CINEMATOGRÁFICA DE LA INFANCIA EN COLOMBIA
}

En Colombia, la ausencia de la niñez en los análisis históricos, particularmente, se comienza a cuestionar desde los años sesenta y setenta del siglo XX. La insuficiencia de los tradicionales análisis en las historias económica, política y social que hasta ese momento predominaban para responder a determinadas preguntas acerca de la realidad social tan compleja del país, atrajo el interés de profesionales y universitarios que se formaban en esta disciplina para explorar nuevos temas y actores que se desarrollaban con un ritmo acelerado en otras latitudes: Francia, Inglaterra, Estados Unidos e Italia en el marco de enfoques como: la vida privada y la intersección de las categorías género, raza o clase ${ }^{15}$.

15 Este cambio de paradigma sienta sus bases en cuestionamientos que se hicieron desde la tercera generación de la escuela de los Annales ( 1929 ) a la historia positivista, al tiempo que se construyeron las bases de una nueva historia social caracterizada por la crítica del "hecho histórico" y a una historia de acontecimientos; la búsqueda de colaboración con otras ciencias sociales; el reemplazo de la historia-relato por la historia-problema, y la atención sobre la historia presente. 
Así como la familia, el matrimonio, la sexualidad, el patriarcado, los grupos de edad, los grupos secretos, las formas de sociabilidad y la sensibilidad, el carnaval y la fiesta, la embriaguez, la diversión o la religiosidad; la infancia se desveló como una parte de la historia que no había sido leída antes, un tema digno que debía ser estudiado ${ }^{16}$. Esa ausencia se puede explicar por el hecho que a los niños poco se les nombraba en documentos escritos (hasta el siglo XVIII), aquellos sujetos de menos de 10 años, solo se convirtieron en el siglo XX en el ser preciado y valorado. En este sentido:

Debido a la altísima mortalidad infantil que existía, a los niños no se les amaba. Era tanta la fragilidad de los bebés y la facilidad con que fallecían, que pareciera que los padres solamente se sentían animados a desarrollar sentimientos profundos hacia sus hijos cuando cumplían el tercer año. (Rodríguez, 2004)

Desde ese punto de vista es posible ubicar trabajos como los de DeMause (1991) y Ulivieri (1986), que sitúan la infancia de la mano con el desarrollo de las capacidades de sentir, pensar y tomar decisiones que los niños pueden lograr exclusivamente en el mundo de los adultos, solo cuando se accede a este mundo, se comienza a formar parte de la

16 Este hecho se inaugura con la publicación de la obra de Philipe Ariès El niño y la vida familiar en el Antiguo Régimen, en 1960. No obstante, desde un corte feminista Simone de Beauvoir ya había incursionado en las etapas de la vida en el Segundo sexo, publicado en 1949, con énfasis en el cuerpo de las mujeres: como niñas, ancianas, madres, solteras. historia; en consecuencia, al negarse con todas sus características, tampoco existía su historia.

Esta nueva preocupación se interpreta como un esfuerzo por integrar y no sobreponer las historias económicas, demográfica, política o social; como:

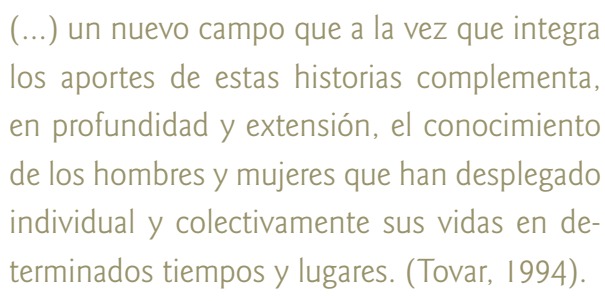

Esto quiere decir que al plantearse la infancia como objeto de investigación y a los niños como nuevos sujetos con nuevas voces, deben incluirse factores sociales, conflictos de poder y dominación que por desgracia estuvieron relegados a raíz de las grandes batallas o los heroicos próceres quienes se apropiaron de la historia. Así mismo, se debe prever que hoy en día esta etapa de la vida se encuentra regulada por la ciencia médica, la educación y una parte de las políticas y fondos públicos.

En función de lo anterior, este capítulo busca detectar y describir las múltiples formas de representación que de los niños y la infancia surgen en el cine, como un producto cultural que a la par de la literatura o la televisión, circunda la esfera comunicativa y de entretenimiento en nuestra sociedad. En otras palabras, se busca reconstruir el papel del cine colombiano en la producción de narraciones que desde diferentes lenguajes sea escrito, iconográfico o sonoro recogen la figura histórica de la infancia desde 1922 a 2013, en donde las formas de representación cultural van unidas a una notable ampliación del horizonte en el campo historiográfico y a los aportes en la sociología y la literatura.

Siguiendo la propuesta de Muñoz y Pachón (1988, 1991, 1996) las concepciones de la infancia no han sido estables sino, más bien, se construyen como variables dependientes de las distintas condiciones socio-históricas. Esta perspectiva facultó al presente estudio para escribir sobre la vida de los niños poniendo de relieve las diferencias que existen entre ellos mismos. Es decir, la niñez no existe como grupo homogéneo, dejando claro que "el niño", en singular tiene una identidad irreal porque "ellos" existen como sujeto múltiple y se aleja de una simple concepción de género.

A continuación, se presentan las representaciones de la infancia a partir de tres momentos temporales: 1922 a 1940, 1941 a 2000 y de 2001 a 2013. Esta división prevé respectivamente la articulación analítica con los regímenes estéticos desarrollados por Jameson (2002): mirada colonial, burocrática y posmoderna en los que fue posible insertar tradiciones, instituciones y formaciones, vitales para comprensión de la relación infancia-cultura como interrelaciones dinámicas que se dan en la sociedad. Los tres momentos coinciden en una serie de prácticas culturales que responden a un estilo de vida residual, empero, cuyos contenidos están determinados por un contexto histórico. 


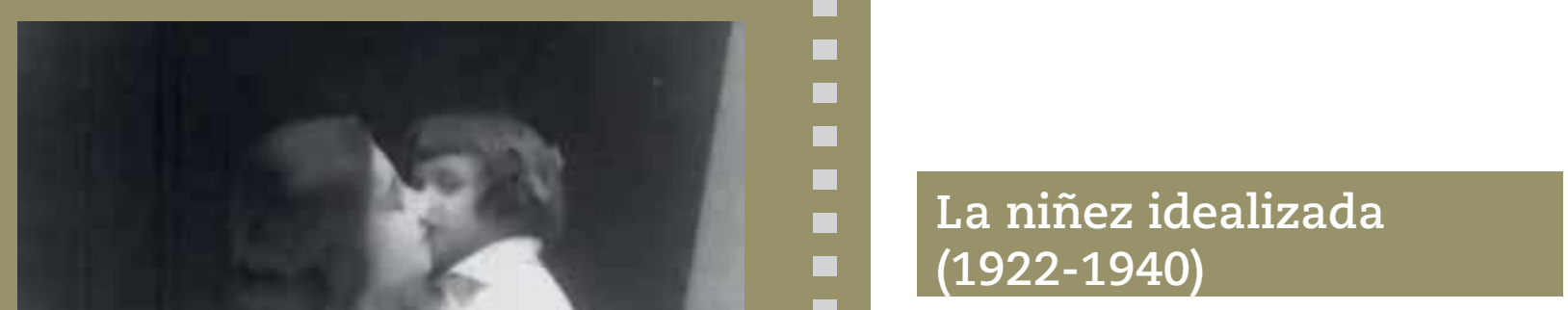

La infancia -en general- siempre ha existido; para el

Fotograma 23 Dando un beso a su madre La tragedia del silencio - Acevedo (1924).
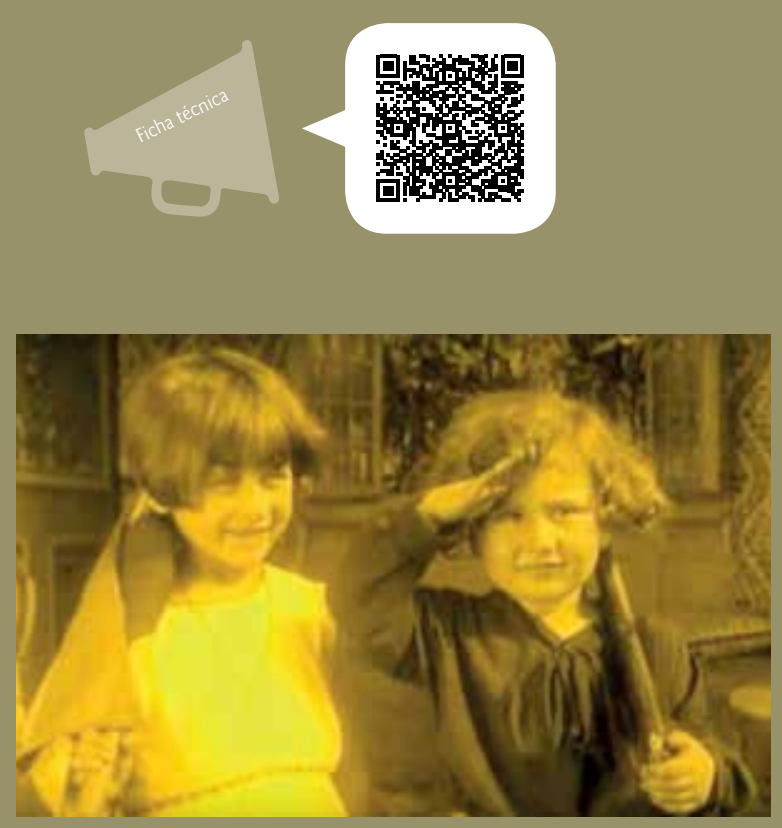

Fotograma 24 A discreción, atención, firmes. Garras de oro - Martínez (1927).

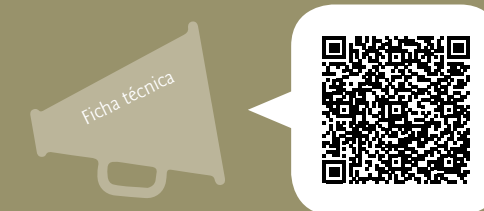
caso particular, en Colombia durante la Colonia, la mayoría de nacimientos se presentaban en los meses de agosto, octubre y mayo:

no se mantuvo ausente. Debemos aclarar que en los inicios del cine en Colombia:

Hacia 1915, año en que se tiene noticia de la película El drama del 15 de octubre de los hermanos Di Doménico. Esta película mostraba los temores patrióticos y sentimentales de la Colombia de principios de siglo. Su objetivo era hacer un homenaje por el magnicidio de Rafael Uribe Uribe, acaecido el año anterior.

(Cogollo, 2015)

Así, en medio de las realidades sociales y culturales en la década de los años veinte se irá descubriendo esa parte de la historia que debía ser leída.

En La tragedia del silencio ${ }^{17}$ bajo la dirección de Arturo Acevedo Vallarino (Fotograma 23), la historia parece estar centrada sobre el drama vivido por un hombre que estaría contagiado de lepra. Un diagnóstico que llevan al hombre, un ingeniero, que trabaja para una empresa ferroviaria a un intento de suicidio. Posteriormente es desmentido, superando entonces la adversidad y consigue salvar su amor conyugal. Por su parte, en Garras de oro (Fotograma 24) P.P. Jambrina (Alfonso Martínez Velazco), es el seudónimo, que firma como director de la cinta. Si mos sujetos de derechos como se intentó vislumbrar desde la segunda mitad del siglo XX. En este sentido, durante el recorrido de este título se presentarán las representaciones que de la infancia surgen en dos largometrajes: La tragedia del silencio (1923) y Garras de oro (1927), en tanto fueron las primeras en proyectarse en el país, que sin darle mayor protagonismo a esa parte de la vida considerada "frágil"
17 De acuerdo con una entrevista realizada a Gonzalo Acevedo, La tragedia del silencio, es uno de los primeros largometrajes colombianos, filmado en estudios provisionales, en el interior de la casa del llamado cura Moreira, en el sitio que hoy ocupa el teatro Colombia, con la primera cámara Pathé que llego a Bogotá. Fue revelada en la sección científica de la empresa de aviación Scadta y se estrenó en el teatro Faenza en 1924. 
bien fue revelada en el año 1927, la trama transcurre con los hechos de finales del siglo XIX y principios $X X$, momento en que Panamá se separó de Colombia con la intervención de los Estados Unidos.

En la medida que el interés de este texto se concentra en los niños como nuevos sujetos con nuevas voces, se ilustran detalles del contexto en que se producen las películas, pues forman en conjunto los rituales religiosos, políticos, culturales, festivos, privados con que el cine colombiano, desde sus inicios, ha representado los hechos de la vida social de los niños y por supuesto los imaginarios ${ }^{18}$.

La infancia representada por estos dos largometrajes forman parte de una categoría:

Orientada por intereses sociopolíticos; in cluye, bajo diferentes figuras encubiertas, una aparente uniformidad que ha permitido concebir proyectos educativos elaborados en función de grupos de edad y prestigio, y que hace viable códigos científicos tales como los discursos pedagógicos, la medicina infantil o la psicología evolutiva. (Álzate, 2003)

18 Los imaginarios sociales surgieron como señala Bravo (2007), en condiciones que posibilitaron el reconocimiento de lo imaginario en la sociedad, tales como la aparición de corrientes alternativas a la racionalidad científica dominante, el reconocimiento de la naturaleza simbólica de la realidad social, el papel de la intersubjetividad y el consecuente interés en el lenguaje y la comunicación, así como los estudios de los fenómenos cotidianos y el desarrollo de la perspectiva hermenéutica.
En función de lo anterior, se encuentran en este momento aspectos como: a. una ciudadanía postergada, pues la infancia no es un tema de importancia, sin derechos y "aún no es capaz" para ejercer la participación y el protagonismo ciudadano; los símbolos patrios, el régimen militar y la infancia constituyen la utopía de un mejor país (la niñez como futuro y no como presente), b. la presencia e influencia de los manuales de urbanidad en la sociedad frente a la constitución; que definían los preceptos por seguir para llevar una vida "cristiana". Textos como el "Manual de Carreño" (1853) o "Consejos a una niña" (1878) de José María Vergara y Vergara (1831-1872), evidencian la preocupación por la educación moral y religiosa, así como por su higiene corporal, y, c. la tradición de la religión que transpone la mirada de la infancia con la analogía al Niño Jesús (en Colombia: Divino Niño), y el lugar de las mujeres (como cuidadoras) frente a la figura del niño.

La idea del Niño Jesús sugiere especial atención, ya que junto con la del Ángel Guardián, forman parte de las imágenes, tradiciones y más adelante, de los discursos que ayudaron a la construcción de la infancia, a fijar el significado de sus enunciados. No obstante, ese significado que se le otorga va a existir en función de una diferencia: bueno/malo, es decir, como el día no puede pensarse sin la noche, o el blanco sin el negro, lo femenino/masculino, la clase alta/la clase baja por mencionar algunos ejemplos. Por tanto, el niño es ángel o demonio, hijo de Dios o hijo del diablo.

La dicotomía entre niño bueno o niño malo cumple un papel fundamental en la forma en que se representa esta etapa de la vida y los lugares que le corresponden, ya que pueden ser significativamente diferentes. Sin embargo, esta oposición crea una relación de poder. En otras palabras, coexiste un polo usualmente dominante: el niño bueno, con sus virtudes de inocencia y amabilidad, que se prolongará desde finales del siglo pasado hasta llegar a nuestros días.

Así, la infancia pasa a propender de los padres, maestros y sacerdotes, una trinidad educadora de la época y constituyen aquellos pilares en los que la sociedad depositó la responsabilidad de perfeccionar esos maleables e imperfectos, irreflexibles y frágiles y encauzarlos por el camino de la vida racional y cristiana (Muñoz y Pachón, 1991). Eso quiere decir que la infancia es pensada como algo que está "fuera de lugar", que desestabilizaba la cultura, por tanto, debe ser barrido y tirado, se debe restaurar el orden y restablecer los asuntos a su normalidad.

De esta manera, los niños, hijos de Dios se convierten en hijos de la patria. Estas representaciones constituyen la base para el desarrollo de una nueva conciencia sobre la infancia, que pasa a entenderse como el futuro de la nación, objeto de atención y cuidado por parte del Estado, ya que más adelante servirán a los intereses de este.

Varios ejemplos se encuentran en Garras de oro, pues los hijos del señor Paterson (protagonista), periodista norteamericano del periódico The Word, que aparecen casi al final, retoman elementos como la bandera de Colombia, un fusil y hasta entonan el himno nacional. Si bien en el trasfondo se trata 
de denunciar a una fuerza extranjera que buscaba ejecutar un proyecto interoceánico para beneficiar el crecimiento de su economía en detrimento de la soberanía y dignidad colombiana; los niños (aunque no existan) pasan a representar un futuro que se creyó despedazado y abatido.

Las anteriores imágenes de acuerdo con Jameson (2002), exponen una mirada colonial o colonizadora, de la visibilidad como colonización, pero a la vez añadiendo nuevos problemas de representación. Sin duda alguna, exponer la infancia es clave históricamente, "pero no es lo mismo la subjetividad de una persona histórica que filma, que atribuir esa subjetividad al resto de la cultura, lo cual sería semejante a la atribución de subjetividad que se hace con un carácter ficticio” (Buxó y de Miguel, 1999).

\section{La infancia que se ve, se dice, pero aún se niega (1941-2000)}

Mediante Ley 12 de 1991, el Congreso de la República de Colombia por primera vez ratifico su compromiso con la Convención Internacional de Derechos del Niño adoptada por la Asamblea General de las Naciones Unidas el 20 de noviembre de 1989. Desde entonces todo "menor" de dieciocho años de edad tendría derecho a la protección y a la formación integral, se les garantizaría participación en los organismos públicos y aún más en aquellos de carácter privado que tuvieran a cargo la educación, protección y progreso de la juventud.
Aunque desde inicios del siglo XX el Estado comenzó a demostrar que los niños eran deseados $y$, en cierta manera protegidos, tuvieron que pasar muchos años más para que las políticas sobre la niñez se comenzaran a desarrollar. Fue hasta el año 2006, mediante Ley $1098^{19}$ que se expide un código nacional cuyo texto garantiza a los niños y a los adolescentes su pleno y armonioso desarrollo para que crezcan en el seno de la familia y de la comunidad, en un ambiente de felicidad, amor y comprensión. Prevaleciendo el reconocimiento a la igualdad y la dignidad humana, sin discriminación alguna. No obstante, hasta su ratificación, la realidad era otra puesto que los niños seguían muriendo, y comenzaban a ser integrados a una parte del mundo de los adultos: el mundo laboral.

Partiendo de las representaciones del Niño Jesús y del Ángel Guardián que se forjaron desde inicios de siglo, surgieron los estereotipos ${ }^{20}$ de la niña como dedicada a las labores de la casa, sumisa, frívola, objeto sexual y obediente. Del niño como trabajador, fuerte, jefe de familia, proveedor y agresivo. Aún

19 La Ley 1098 de 2006 también es conocida como: Código de la Infancia y Adolescencia

20 Se entiende el concepto de estereotipo como una "práctica que reduce a la gente, objetos o lugares a características simples y esenciales que son representadas como fijas por parte de la naturaleza" (Hall, 20I3, p. 442). Los estereotipos son los que terminan dándole sentido al mundo, y solo se le puede entender porque forman parte de esquemas de clasificación generales en los que, de acuerdo con nuestra cultura, encajan. Se puede decir entonces que los estereotipos son esenciales para la producción de significado. más, basados en la clase social como ignorantes y asociados a la delincuencia.

Este título se ocupará de un conjunto de películas que forjan ideas del niño como menesteroso, gamín o anormal aclarando que es una clasificación arbitraría. También, es posible que se revisiten situaciones desde lo económico como condición de orden social, que genera una división entre infancia de primera categoría (los que tienen familia, hogar) y de segunda categoría (niños de la calle o en situación de vulneración); el impacto en el desarrollo e implementación de políticas neoliberales que conlleva a la inestabilidad de las familias, razón por la cual se empieza a ver el fenómeno de los niños abandonados, los niños en situación de calle, los niños trabajadores, y otras formas de segregación como los niños homosexuales.

\section{Menesterosos}

La pobreza siempre ha estado presente en la sociedad colombiana, no es un fenómeno nada nuevo y se ha acentuado en épocas de crisis como sucedió, por ejemplo, después de la Independencia (1810), seguida por un largo periodo de estancamiento económico; luego de las guerras civiles (1830-1902), de desastres naturales e inclusive de las enfermedades tanto endémicas como epidémicas, conocidas como pestes. Hasta los años cuarenta del pasado siglo, la mayoría de la población colombiana era rural, fue un momento de rápido crecimiento y desenvolvimiento demográfico, así como la consolidación de procesos de urbanización que habían sido incipientes durante los últimos años del siglo XIX (Castro, 1997). 
Este contexto fue aprovechado por los realizadores del cine para plasmar sus ideas, imaginarios y discursos frente a una realidad que se podía ver, pero en ciertos casos negar: los pobres de la ciudad, quienes trataban de ocultar su miseria, aún más, se encerraban con sus hijos en habitaciones desmanteladas, sufriendo en ellas los horrores del hambre y la desnudez. Se trató así, de un momento propicio para que los encargados de la producción, la puesta en escena, la ambientación o el vestuario, elaboraran narraciones en torno a las mujeres y los hombres en todas las edades de la vida. Como la juventud o la vejez, la infancia recreada por individuos entre los 0 y 18 años de edad, no fue la excepción.

Así, nos encontramos con las películas Dos ángeles y medio (1958), producida por Demetrio Aguilera Malta, El niño y el papa (1986) de Rodrigo Castaño y el documental Los chircales (1972) de Marta Rodríguez y Jorge Silva. En los dos primeros casos (Fotograma 24 y 25) aparecen distintas variantes de los personajes, por un lado, la narración de dos niños de la calle que tienen que cambiar el destino, por accidente, de un bebé nacido en una familia adinerada de Bogotá (abandonado por sus padres, descuidado por la niñera). Y por el otro, de un niño de la Ciudad de México que busca aliciente a raíz de la pérdida de su mamá (en el terremoto de 1985) a través del santo pontífice, Juan Pablo II en su visita a Colombia el primero de julio de $1986^{21}$.

21 Este cameo se realizó en la visita de Karol Wojtyla a la capital colombiana; una semana después del hito histórico conocido como: La toma del Palacio de Justicia u Operación Antonio Nariño por los Derechos del Hombre; y se toman fragmentos de la
Estas ideas del niño expósito y huérfano, sientan sus bases desde la época colonial, cuando "es recluido bajo todos los afectados en el servicio de los pobres, quienes eran vistos como parte de una plaga de enjambre de mendigos que aumentaba la población. A esto se hacía imperante la demanda de subsistencia mediante clamores y la posibilidad final, para el caso de los niños, hacerlos útiles en los hogares sustitutos" (Jiménez, 2013).

En Dos ángeles y medio, película que se desarrolla en medio de una soleada tarde bogotana, el trasfondo pareciera ser un llamado o quizás una denuncia social al descuido de la familia, en especial, de las madres que para la época estaban obligadas a hacer todo por la vida del niño ${ }^{22}$. Esta mirada reflexiva desde la categoría que es objeto de interés en este título, nos remonta a esa infancia representada en las imágenes y discursos del Niño Jesús y del ángel de la guarda que mencionamos anteriormente. De entrada un niño blanco, de familia adinerada, nuestro "medio ángel”, más adelante dos niños habitantes de la calle (uno era actor natural) que deambulan las calles bogotanas y donde es posible ver algunos de sus lugares representativos como el Hotel Tequendama, el barrio Santa Ana y La Candelaria en el centro de la capital colombiana.

Ahora bien, ¿qué hace a aquel niño, un "medio ángel” y a los otros dos niños, un ángel completo?

oración realizada por el pontífice a los difuntos de la tragedia de Armero (desastre natural ocurrido en noviembre de 1985).

22 Se puede ver que la película comienza con la canción Madrecita querida en la voz de Chito Galindo.

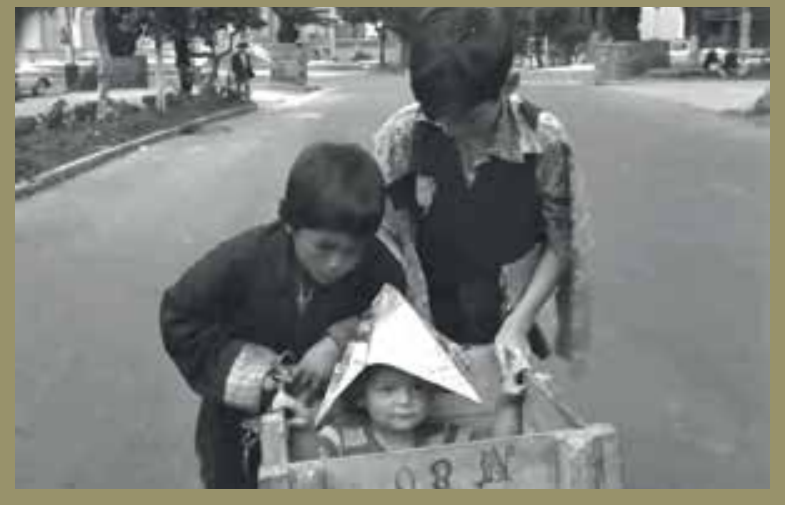

Fotograma 25 De paseo por la ciudad. Dos ángeles y medio -Aguilera, (1958).
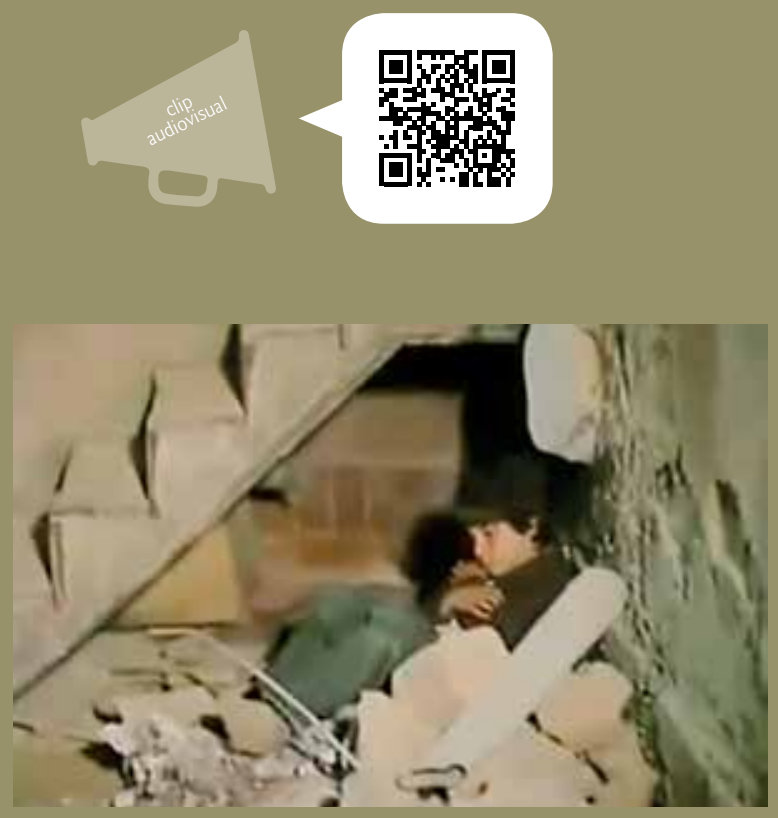

Fotograma 26 Dolor entre los escombros. El niño y el papa - Castaño (1986).

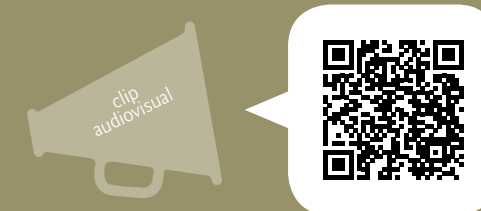




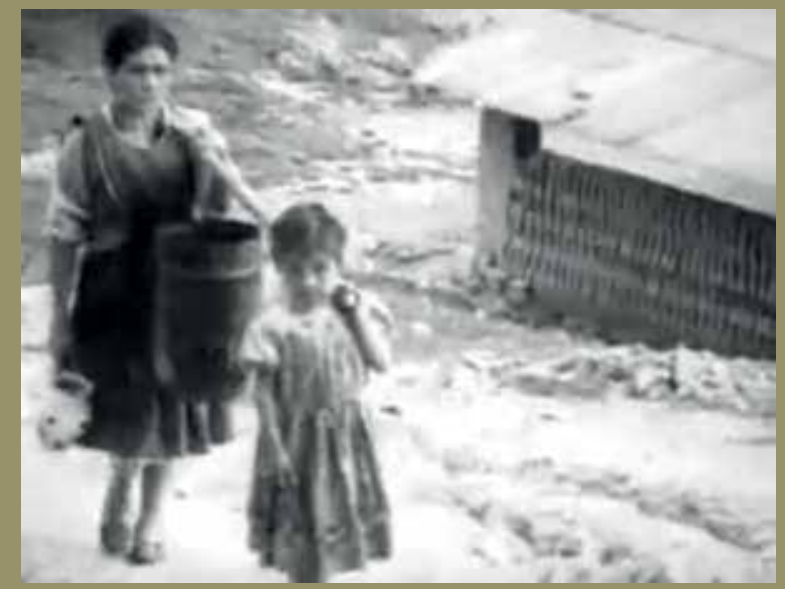

Fotograma 27 Aguateras del siglo XX. Chircales - Rodriguez y Silva (1972).
Es claro que a pesar de las precarias condiciones de ellos, de sus vestidos harapientos y de vivir en un tugurio, sus acciones de cuidar a aquel niño que se pierde en el Parque Nacional; y sus constantes sueños (juegos en el parque de diversiones, una alegre Navidad con mucha comida) reflejan las virtudes de inocencia y bondad, propias del hijo de Dios. Reemplazar los conceptos de pecado y maldad, la imaginación como un mal hábito, las fantasías y sueños como algo que debía combatirse o los juegos como tiempo perdido, fue un asunto de tiempo en tanto se ensanchó una lucha entre la visión religiosa y militar; y las instituciones y la visión educativa, sanitaria, laboral y psicológica (Muñoz y Pachón, 199I, 1996). Por su lado, nuestro "medio ángel”, inspira dulzura y pareciera que hablará de la voz interior de la conciencia para que los otros dos optaran por lo debido, es decir, entregarlo al seno de la familia y no cambiar su destino.

En El niño y el papa, nuevamente aparece el ángel, pues el protagonista se llama así "Ángel" o "Angelito" en su forma hipocorística. A diferencia de los anteriores, el personaje gana mayor protagonismo no solo porque su voz es escuchada y tenida en cuenta (por Carmen que le canta al papa, don Fulgencio que ayuda en la composición de la canción e incluso la vendedora cerca de la catedral), sino porque además aparece la figura del santo pontífice a mediar en el sueño que tiene él, que es reencontrarse con su mamá. En este sentido, aunque se va a producir un cambio sustancial respecto a la concepción que se tiene de la infancia, el asunto de lo bueno y malo sigue presente.
Los chircales (Fotograma 27) muestra a la infancia como una etapa del ser muy corta, pues los niños son integrados al mundo de los adultos, a sus trabajos, en este caso: la elaboración rudimentaria de ladrillos. Las condiciones sociales, políticas y religiosas de la época, dejan ver a un conjunto de obreros que acuden a los arrendatarios en búsqueda de dinero y así trabajarle a los grandes terratenientes que más adelante los explota (bajos sueldos, largas jornadas laborales, exigencias de elección política), al mismo tiempo, las tradiciones que enmarcan a las extensas familias como la de no hacer uso de la planificación familiar (que ya existía), pues "eran los hijos que Dios mandara"; y la importancia de los sacramentos en la vida del niño o la niña. En este documental aparece la primera comunión como un rito imprescindible para que en su corta edad puedan estar libres de pecado y por tanto convertirse en hijos de Dios y no del diablo.

\section{Gamines}

La presencia del gamín en la cinematografía colombiana se puede ubicar en el documental homónimo Gamin (1977) de Ciro Durán y La vendedora de rosas (1998) película de Víctor Gaviria. En los dos, es posible abordar su emergencia, objetivación discursiva por parte de varias prácticas disciplinares, instituciones y sujetos de saber, y también su emergencia como sujeto, que han sido objeto de estudio por parte de Jiménez (2013). Aquí, la atención se ocupará en esa objetivación discursiva que ha dado pie a diferentes representaciones.

$$
-74-
$$


En la primera (Fotograma 28), el gamín es un habitante de la calle $y$, de acuerdo con la narración presentada por Durán, es un individuo que oscila entre los 18 años de edad que rebusca la manera de subsistir en medio de las condiciones que le ofrece el entorno (cantar en los buses, pedir dinero o comida a los transeúntes, robar) y se reúne en "galladas" 23 para buscar apoyo; en la segunda (Fotograma 29) el gamín, deambula entre los problemas de drogadicción, alcoholismo y prostitución. En ambos casos aparecen distintas variantes del personaje gamín, sin embargo, coinciden en las situaciones de violencia (rural e intraurbana, que ocurre entre los límites de la zona urbana como el sicariato); ${ }^{24}$ en los conflictos que muchos viven en el interior de sus hogares con los padres; y en la pérdida de la inocencia, ya que se ven obligados a trabajos forzosos (distribución de droga), poco remunerados (venta de flores), exponiéndose al peligro o la muerte.

Jiménez (2013), apoyándose en investigaciones como la de Álvarez (2002), plantea que en la primera mitad del siglo XX, el tema de los niños en la calle o la infancia abandonada en Bogotá, termina siendo

23 Por definición del narrador, "gallada" es en el lenguaje de los gamines: "una agrupación que entre ellos se forma para enfrentar mejor la rudeza del medio y que permite desarrollar más fácilmente las actividades del gamín"; "La gallada para estos niños llega a ser una familia".

24 Se trata de un fenómeno en auge durante las décadas de 1980 y 1990, asesinos a sueldo que, a cambio de cierto pago, se encargaban de matar a las personas por quien los contrataba. Para ampliar véase la investigación del profesor Alex Schlenker (2012). Se busca. Indagaciones sobre la figura de sicario. Quito: Universidad Andina Simón Bolívar. afrontado por la sociedad, la Iglesia (católica) y el Estado, bajo tres imaginarios: pureza, fragilidad y promesa; que son producto de prácticas que en últimas buscan ubicar al niño abandonado. Ahora bien. en La vendedora de rosas es recreado otro contexto, Medellín, dejando claro que estos personajes se habían tomado las calles de las principales ciudades colombianas, "un problema que se confundió con la industrialización tardía y de la urbanización desordenada que se vivió en nuestro país" (Jiménez, 2013); en esta película dominan las mujeres en comparación de la anterior (Mónica, Andrea por ejemplo), pero sus vestimentas improvisadas o la ilusión de un hogar siguen intactas a la anterior. Esto último, es posible recrearlo con el delirar de Mónica frente a una virgen convertida en la madre que se va flotando entre los llamados de su amiga, desde el otro lado de la realidad (Pérez, 2013).

Aunque ya para el año 1968 se había creado el Instituto Colombiano de Bienestar Familiar ICBF para prever las situaciones de abandono, desprotección y maltrato, como parte de las estrategias del Estado para asistir a la infancia, esto no se ve reflejado en los largometrajes. En otras palabras, se representa una infancia marginal, excluida y pobre que encaja en las dicotomías de bueno/malo, de la calle o la limosna como parte del imaginario de estos individuos.

La presencia de los gamines en la cinematografía nacional incorpora "una historia social, cultural del país. Pero sobre todo una historia política de ciudades como Medellín, Bogotá o Cali. Una historia entretejida con variables de diversa índole, condi-

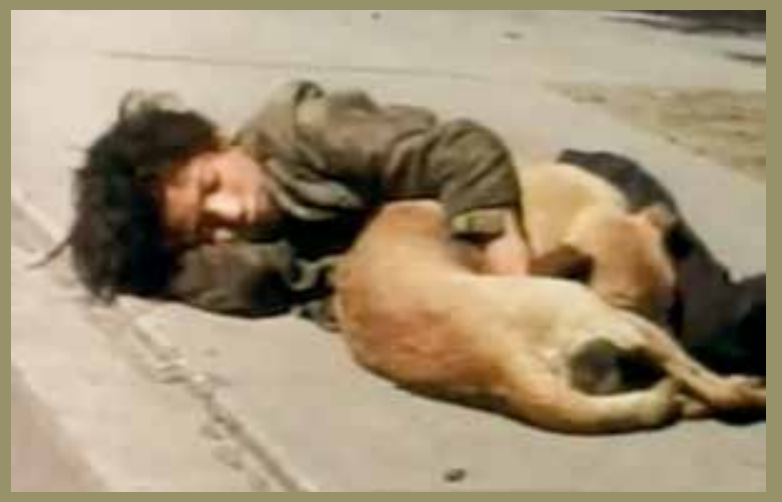

Fotograma 28 Mi amigo fiel. Gamín - Durán (1977)

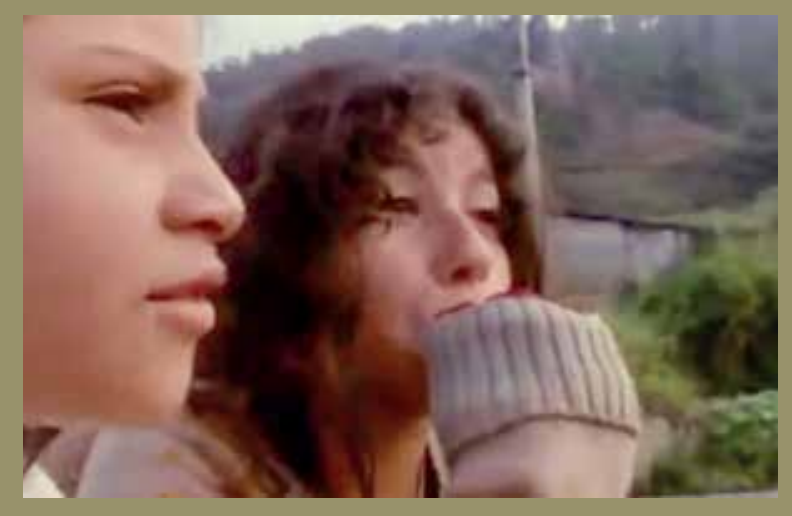

Fotograma 29 Esperando el futuro incierto. La vendedora de rosas. - Gaviria (1998).

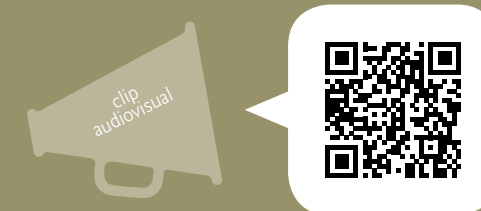




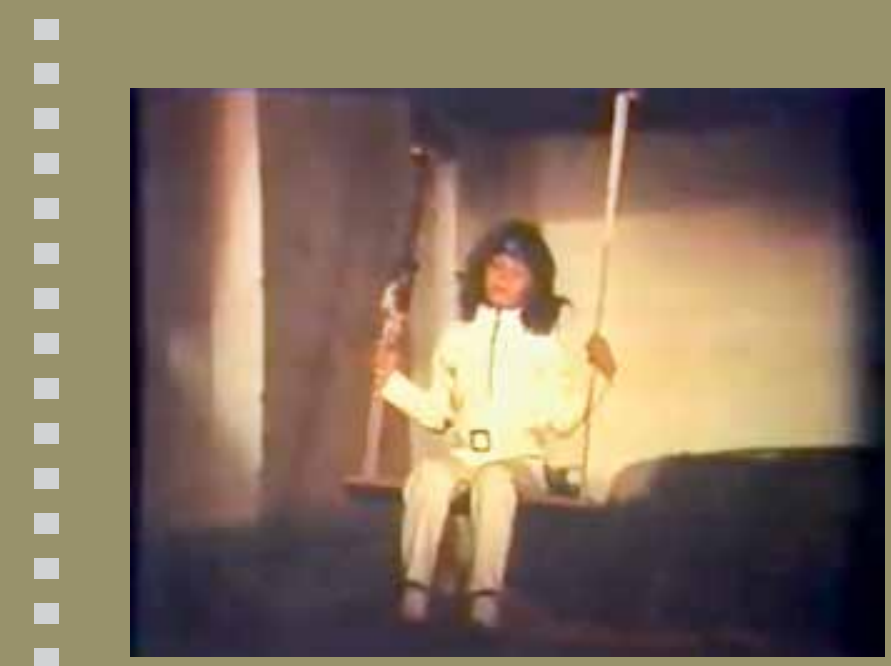

Fotograma 30 Los placeres de la soledad. El muro del silencio - Alcoriza (1974). cionada y proyectada por diversidad de imaginarios sociales alimentados por el paradigma imaginario de la modernidad. Una historia donde la violencia en Colombia tiene un lugar central" (Zambrano y de Cássia, 2014).

\section{Anormales}

El muro del silencio (1974), película realizada por Luis Alcoriza, recrea la historia de un niño, Daniel, que de acuerdo con Acosta (2013) estaría sobre un trasfondo en el que se perciben a veces nítidamente, a veces difuminadas, las prácticas matrimoniales, la trasmisión de bienes, las relaciones entre hombres y mujeres, los modos de afecto, las formas de habitación, las prácticas domésticas, las tensiones sociales $y$ las instancias educativas.

En El muro del silencio (Fotograma 30), la infancia se encuentra mediada por el asunto de la sexualidad, que por mucho tiempo estuvo reducida a las necesidades biológicas. Así mismo, de un sistema que separa a uno y otro sexo, sus modos de ver, de sentir y actuar. Aunque no explícitamente, la película de Alcoriza trata sobre la homosexualidad, es claro que el personaje principal se debate en aquella práctica que la cultura va a separar por ser no apropiada e inmoral, frente a la heterosexualidad que es apropiada.

Daniel al tener cabello largo, usar ropas propias del hombre, y asumir los atributos del cuerpo femenino y la feminización como la comprensión, delicadeza y suavidad, representa los patrones culturales fuertemente arraigados en los diferentes grupos sociales, que establecen una clara diferenciación entre masculinidad y feminidad. La primera por supuesto hegemónica, donde se construye a la heterosexualidad y se garantiza un modelo de relación social entre los sexos en el que el cuerpo de las mujeres es siempre accesible para los hombres. Nos obstante, este modelo reduce las expresiones de la sexualidad a posiciones de dominación: activa o pasiva.

Este "ángel hermafrodita", aislado de la sociedad, de los pecados y peligros, pues es la madre quien lo cuida y educa, representa a los niños sobre los cuales, que como sucedía con los locos, los enfermos, los criminales o los pobres actuaban mecanismos de poder, fundados en lo que Foucault (2000) menciona como la descalificación, posteriormente el exilio, el rechazo, la privación y el desconocimiento. Por esta razón se asiste con interés a reproducir y a revalorizar los estereotipos de los hombres como fuertes, independientes, valientes, competitivos y líderes vistos a través del personaje en escenas con sus primos, el tío y más adelante en el acto que lleva a la muerte de la madre.

La infancia de Daniel representa las prácticas no apropiadas, los aspectos de sexualidades y las expresiones de género no normativas, una amenaza a la identidad colectiva. Toda persona que rompa con su posición de masculinidad/feminidad, o que presente formas de sexualidad no hegemónicas se percibe como una amenaza al colectivo, y ponen en cuestionamiento las prácticas de género y deseo dominantes. Debemos aclarar que estos cuerpos, y deseos, se asientan en los espacios concretos que habitamos en lo cotidiano y muchas veces terminan impactando de forma compleja en nuestras vidas.

$$
-76-
$$


Se ha visto entonces como un conjunto de películas han contribuido al fortalecimiento de una noción más amplia de la categoría de infancia, pero en su apuesta de re-construir al sujeto niño o niña, hombres y mujeres en sus gustos, ideas y formas de pensamiento han creado estereotipos e imágenes que transitan desde lo social a lo político, unas veces sin proponérselo y otras intencionalmente. De esa manera, estaríamos en frente de lo que Cogollo (2015), citando a Oswaldo Osorio "es el espejo de la vida, función de su reflejo es justamente que la gente se vea en él y estando frente al espejo, es decir, frente a la pantalla, observando lo que en ella ocurre, entonces tendrá otra perspectiva de la realidad, sobre todo por ese acercamiento y esa forma de entenderla que propone cada director (...)" (Osorio, 2010).

Así mismo, es posible ubicar la mirada burocrática, que busca por doquier la mensurabilidad del Otro y su mundo, de aquí en más reifícados. De esta manera:

La identificación del conocimiento con el poder y de lo epistemológico con la política de la dominación, tiende a disolver lo político mismo como una instancia o posibilidad de praxis independiente, y al convertir todas las formas de conocimiento y medición en formas de disciplina, control y dominación, en sustancia elimina por completo lo más estrechamente político. (Jameson, 2002)

\section{La infancia caleidoscópica (2001-2013)}

Bajo el título de nuevas sensibilidades, motivaciones y preocupaciones, se han agrupado un conjunto de películas que creadas entre el año 2000 hasta el 2013, se distanciaron de la infancia en su progresiva analogía con la religión católica, de lo demoníaco y lo divino, cediendo paso a las tensiones entre lo étnico y lo cultural, aún más, a los problemas que en algún momento se pensaron "exclusivos" de las grandes ciudades, y no del campo o de las pequeñas poblaciones; y a las tradiciones de antaño que forjan hoy la identidad cultural colombiana que comprende:

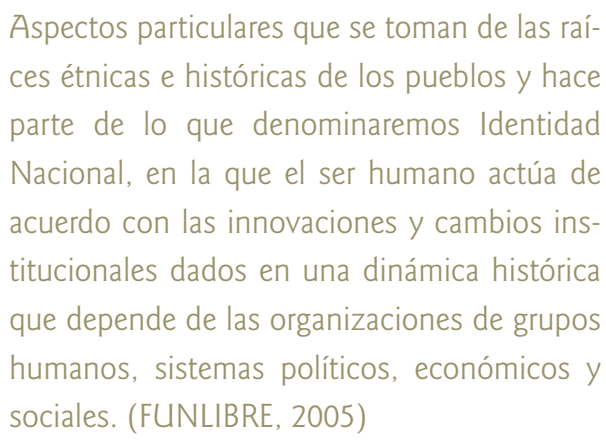

No obstante, son películas que lentamente continuaron con su tarea de construir imaginarios y representaciones sociales, ligados a la moral, la familia, y el ejercicio de poder en la sociedad colombiana.

Para comprender esta nueva forma de fijar una posición desestigmatizada de la infancia en relación con sus situaciones, acontecimientos y objetos se organizaron cuatro subgrupos: el primero, constituido por El ángel del acordeón (2008), Los viajes del viento (2009) y La eterna noche de las doce lunas (2013), una infancia representada por héroes traviesos llenos de energía, fuertes y sobre todo, valientes; el segundo, por Los colores de la montaña (2010) y Pequeñas voces (2010), infancia que representa el poder, la acción y la vigilancia de fronteras, y las cualidades propias de niños guerreros como son la rectitud y el tesón; el tercero, por Chocó (2012), El vuelco del cangrejo (2009) y La playa D.C. (2012); y el cuarto por Los niños invisibles (2001), Te busco (2002), El resquicio (2012), El paseo 2 (2012), El control (2013) y Anina (2013); Los anteriores grupos proponen una mirada plural y dinámica de la infancia, teniendo en cuenta las posibles y diversas versiones de ser niño, anudando lo cultural, lo social y lo familiar, propio del proceso de reconstrucción permanente en el camino hacia la identidad propia. Aunque en ciertos casos rompen con una secuencia temporal, la agrupación responde a criterios encontrados en el desarrollo del análisis de las películas.

Esta notable y significativa ampliación de horizonte en la forma en que se representa a los niños, se da al mismo tiempo que la historiografía nacional e internacional incorpora nuevas categorías para los análisis, que deben pensarse intrínsecamente ligadas si se quiere seguir en el reconocimiento, visibilización e inclusión de sujetos sociales sin historia, ausentes de la reconstrucción nacional, regional o local. Se trata del enfoque de género que posibilita una interpretación de las relaciones de poder que existen entre hombres y mujeres, así como las que se entretejen y anudan entre ellos y ellas mismas, sus tensiones y conflictos; y de la interseccionali- 


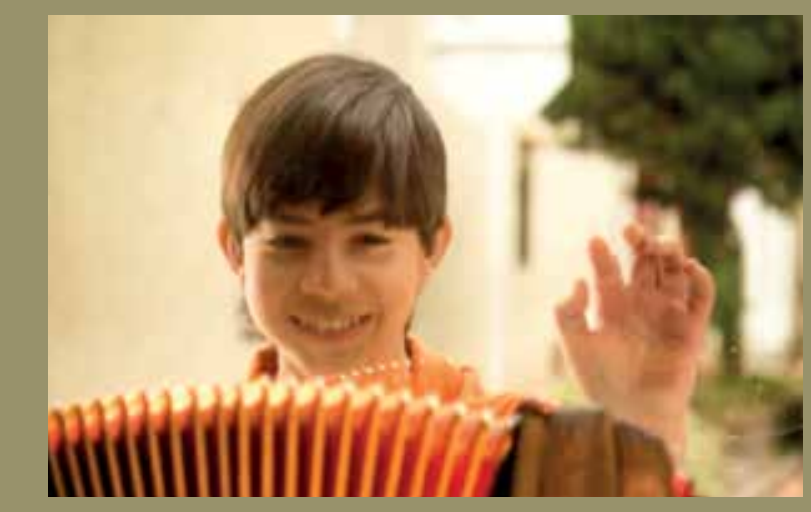

Fotograma 31 Quiero ser rey el vallenato. El ángel del acordeón - Lizarazo (2008).
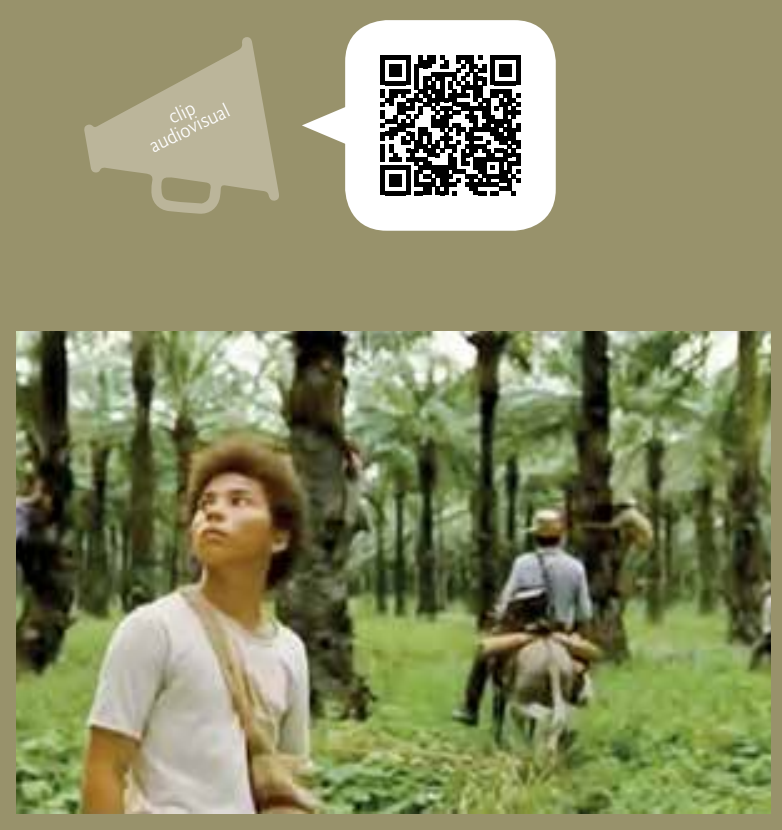

Fotograma 32 Admirando la naturaleza. Los viajes del viento -Guerra (2009).

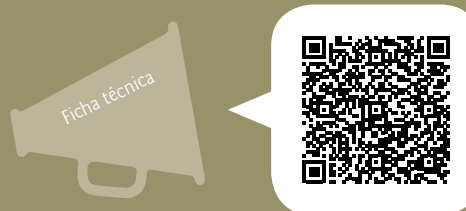

dad, que supone un modelo de análisis de las diferencias sociales, ya que podemos estar hablando de raza, clase o sexualidad.

En este sentido, el primer grupo, compuesto por las cintas El ángel del acordeón (Fotograma 31) de María Camila Lizarazo, Los Viajes del viento (Fotograma 32) de Ciro Guerra y el documental La eterna noche de las doce lunas (Fotograma 33) de Priscila Padilla, sonidos e imágenes del entorno geográfico nos remontan a los orígenes, historias, costumbres, tradiciones y expresiones folclóricas que sincretizan la realidad de diversas zonas de Colombia, en este caso del Caribe colombiano. La infancia en estos largometrajes es representada en función de metáforas como el acordeón o viajes que no solo aluden un desplazamiento físico, sino espiritual. En los dos casos, siguiendo a Pérez (2013), se apunta a la formación de un héroe que encuentra su destino y espíritu en las aventuras que lo moldean.

En El ángel del acordeón, la incansable lucha del protagonista por conseguir su caja musical, lo envuelven en una serie de situaciones y acontecimientos que desde niño lo transforman en héroe y más adelante en una leyenda: perder sus ahorros a raíz del alcoholismo y machismo de su padre, trabajar en el campo, soportar la envidia del compañero de escuela (Pepe), encontrar el primer amor (Sara María), afrontar la separación familiar o ser víctima de robo; en Los viajes del viento, aparece nuevamente aquel instrumento musical, acompañado de un viaje, motivado por un niño en su deseo de aprender a interpretarlo. Así, Fermín, uno de los personajes principales emprende un largo recorrido siguiendo a un viejo que no cree en él, en medio de sus harapientos zapatos, fiestas y peleas que encuentran de pueblo en pueblo que visitan.

En La eterna noche de las doce lunas, documental que merece especial atención, pues forma parte de la preocupación de Mateus (2013) por las modalidades de representación y auto-representación de los indígenas, hecho que ha crecido considerablemente en las últimas tres décadas, estimulando la reflexión sobre la producción de imágenes de los pueblos indígenas; la llegada de la primera menstruación en las niñas, marca el tránsito para convertirse en mujeres adultas, por medio de un ritual que dura un año (las 12 lunas del título). En medio de una ranchería Wayuu, una niña es encerrada, no puede ver ni hablar con hombres. Hecho que étnicamente la transforma en una "buena mujer".

La imagen del niño/niña como héroe, no se constituye a partir de alegorías a la patria como en los largometrajes que conforman el primer momento $o$ en el porte de coloridos uniformes y enhiestos penachos, con el que libran sus gestas y batallas, sino en tanto son depositarios de un discurso que termina afectando la situación de otros sujetos. En este sentido, encontramos a los saberes sociales que dan mayor comprensión y valoración a la tradición popular escenificada en los contenidos de danzas, rituales, arquitectura, comida, música, entre otros, que se mantienen vigente en la memoria (desde temprana edad), así como en algunas prácticas sociales que en el presente se convierten en expresiones artísticas llenas de significado. Los procesos artesanales, son un ejemplo bastante significativo. 
Las películas que se abordan en el segundo grupo enfrentan al drama de la infancia con el conflicto armado en Colombia. Los colores de la montaña realizada por Carlos César Arbeláez y Pequeñas voces de Jairo Eduardo Carrillo, mezclan esto último como un elemento de deterioro para las condiciones de la vida para la población infantil. Ahora bien, cintas como la de Arbeláez (Fotograma 34) ubican la infancia en función de unos arquetipos y estereotipos propios de la masculinidad. En este caso se trataría del guerrero, pues los niños Manuel, Julián y Genaro (Poca Luz) se caracterizan por ser valientes (al intentar rescatar el balón) y muy fríos en la expresión de sus sentimientos: frente a la muerte de los padres, el abandono de la profesora, la pérdida de objetos valiosos o la migración forzada.

De acuerdo con Jiménez (2013), entre los años setenta y ochenta, las guerrillas multiplicaron sus zonas de operación y de conflicto armado en diferentes territorios del país, lo que trajo una respuesta inmediata de los grupos de derecha rural, expresada en la constitución de las AUC (Autodefensas Unidas de Colombia). Mientras que esto pasaba, es claro que los niños tenían prohibido reconocer y expresar la tristeza, el dolor, el miedo o la soledad y debían prepararse para cargar fusiles y llevar vestidos de usanza militar, con sus caras cubiertas con pañuelos, buscando ocultar su identidad.

Esta idea del guerrero también se ve reflejada en Pequeñas voces (Fotograma 35), ya que ser "el fuerte" y "el duro", forman parte de las narraciones de niños desplazados que crecieron en medio de la violencia y el caos de nuestro país. Sus historias evocan

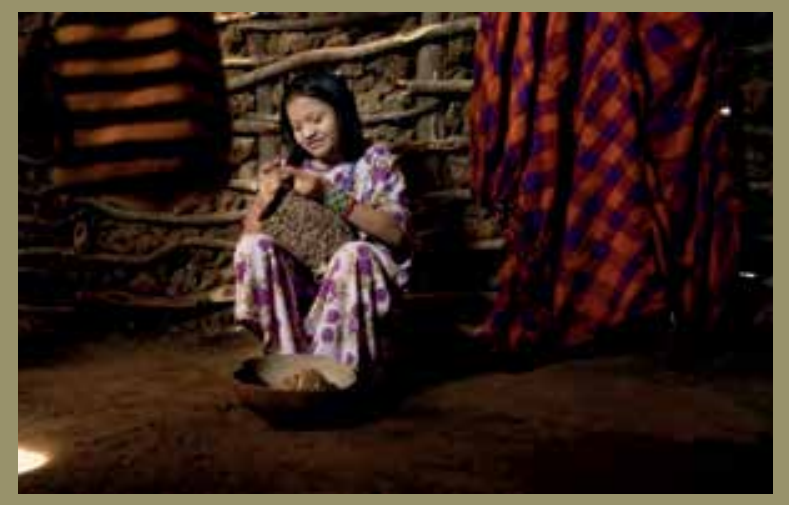

Fotograma 33 Tejiendo memorias. La eterna noche de las doce lunas - Padilla (2013).
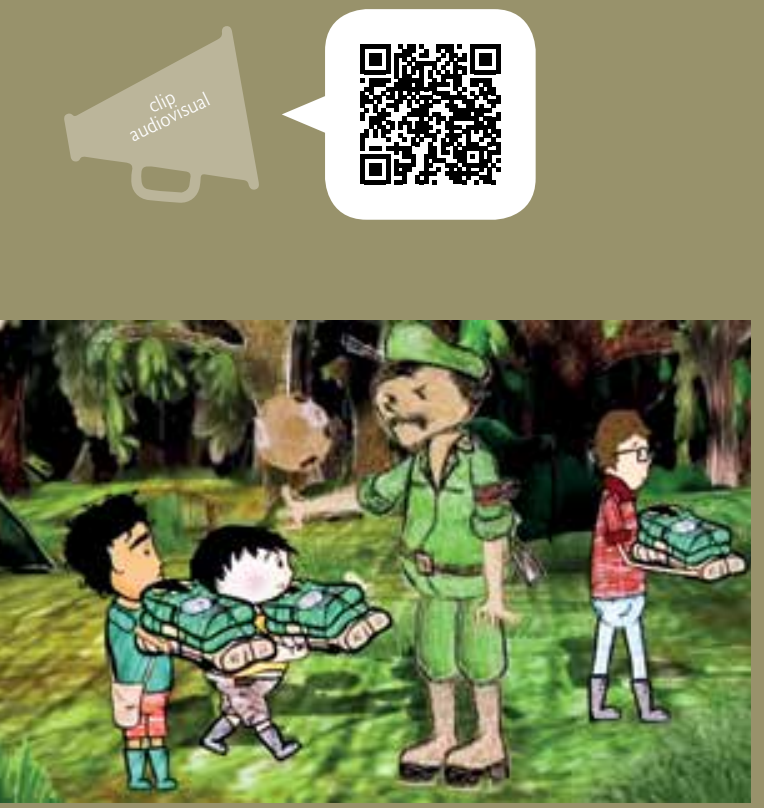

Fotograma 35 Una vida obligada. Pequeñas voces - Carrillo (2010).

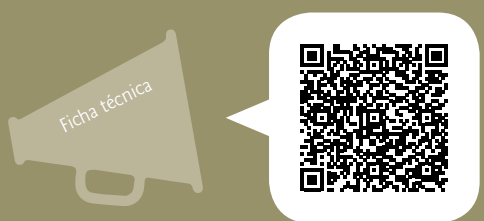

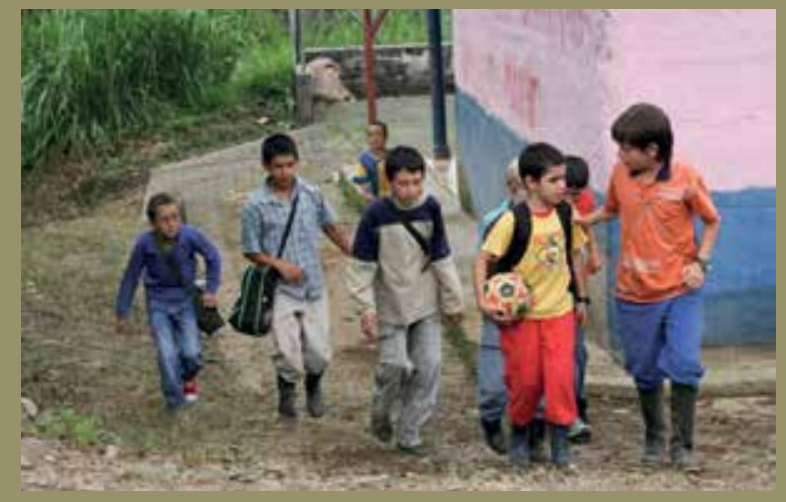

Fotograma 34 Con el "parche" de amigos. Los colores de la montaña - Arbeláez (2010).

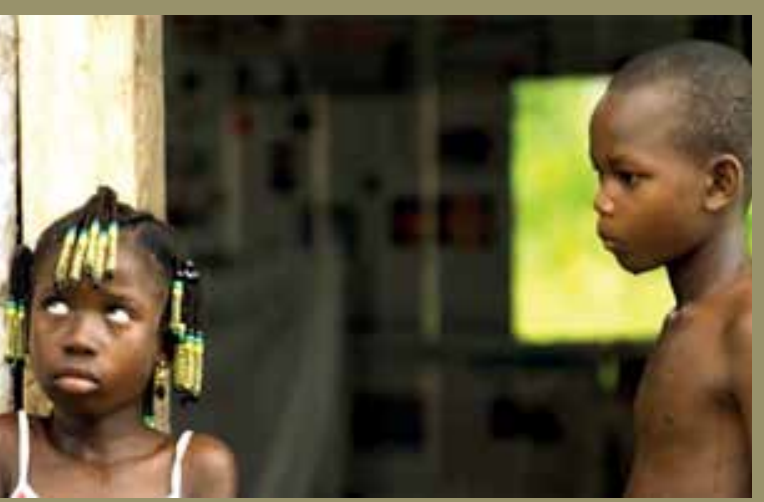

Fotograma 36 Tengo una duda. Chocó - Hinestroza (20/2).

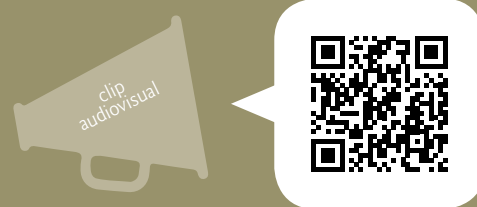


metáfora de la libertad frente a la situación que vive Tomás (en La playa D.C) con su madre luego de que llegaran a Bogotá expulsados de la costa por la guerra, su padre fue asesinado por paramilitares y el hermano menor perdido, Jairo, metido en las drogas.

El último subgrupo, quizás el más amplio, se ubica bajo el espectro de la infancia plural, ese sobre el que advertimos al inicio del documento. Las películas Los niños invisibles de Lisandro Duque, Te busco de Ricardo Coral, El resquicio de Alfonso Acosta, El paseo 2 de Harold Trompetero, El control de Felipe Dorothée y Anina de Alfredo Soderguit, entregan ese punto de arranque. En todo caso, también remiten a mensajes, encargos y características, presentes en las tradiciones y culturas.

Uno de esos mensajes se funda en arquetipos como el del mago, que hace referencia a la sabiduría, a los conocimientos. Los niños, por ejemplo, representados en las películas de Duque (Fotograma 39), Coral (Fotograma 40), Acosta (Fotograma 4I) y Dothée (Fotograma 42), toman esa figura como muestra del poder de convencimiento que ejercen sobre las demás personas o de aquella que siempre se las ingenian para encontrar una solución a los problemas: la invisibilidad para ir por las calles, entrar a cine gratis y ver mujeres desnudas; convencer al papá en el sueño del tío (formar una orquesta de música tropical); de secretos dolorosos y que ninguno quiere aceptar; o de regalar televisores para hacer familias felices. Como sucede en estos casos, así como en El paseo 2 (Fotograma 43) y Anina (Fotograma 44) nos encontramos con que "es el verdadero momento de la sociedad de la imagen, en que

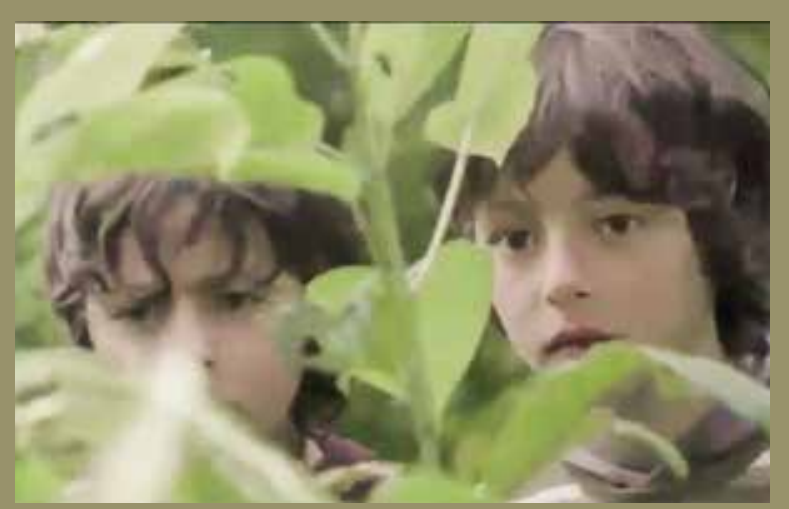

Fotograma 4I La curiosidad mató al gato. El resquicio - Acosta (20/2).
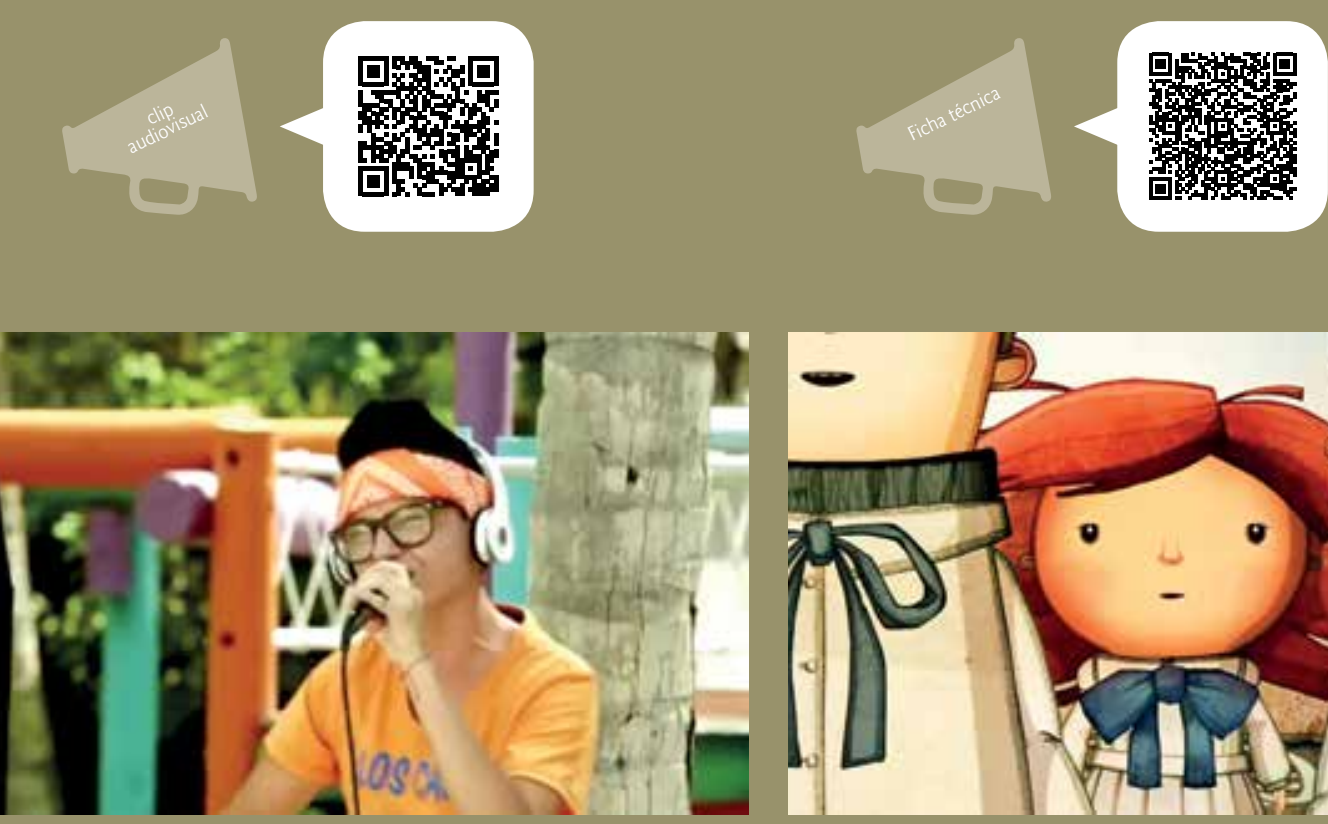

Fotograma 43 Canto alegre. El paseo 2 - Trompetero (20I2).

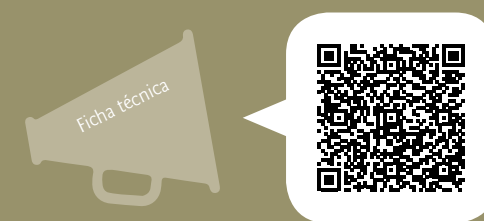

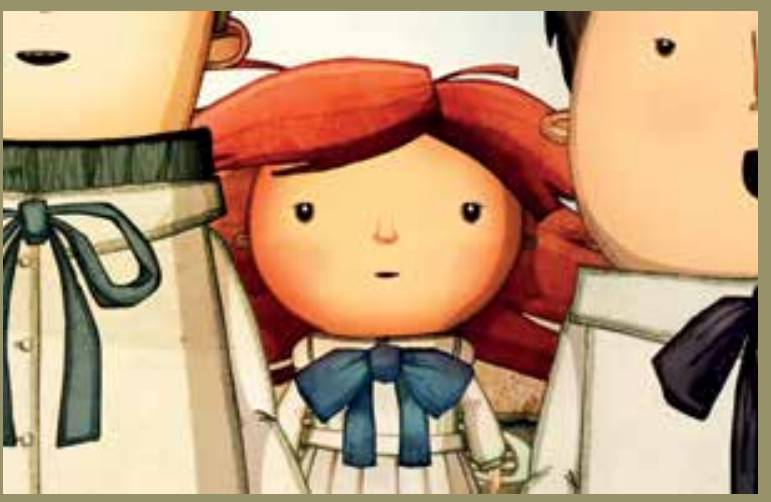
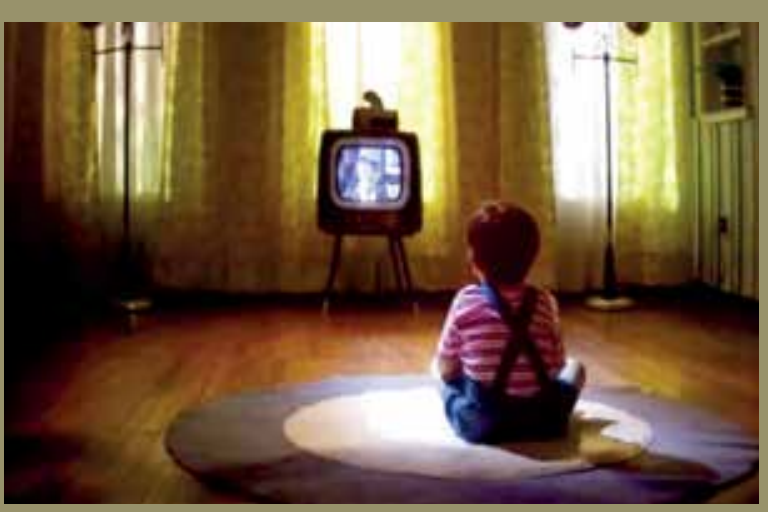

Fotograma 42 Entre el blanco y negro. El control - Dothée (2013).

Fotograma 44 Capicúa. Anina - Soderguit (20/3).

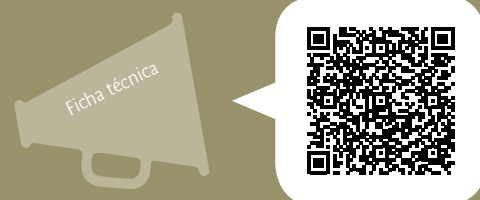


los sujetos humanos, en lo sucesivo expuestos (de acuerdo con Paul Willis) a bombardeos de hasta mil imágenes por día (al mismo tiempo que sus ex vidas privadas se observan y escrutan, pormenorizan miden y enumeran exhaustivamente en bancos de datos), comienzan a vivir una relación muy diferente con el espacio y el tiempo, la experiencia existencia y el consumo cultural" (Jameson, 2000).

Los filmes considerados, comprenden un conjunto que presenta un ejercicio crítico sobre los conflictos de poder al interior de las familias; la niñez y su búsqueda por la identificación en otros actores sociales, las figuras paternas o maternas ausentes; $y$ la generación de nuevos roles para la infancia. Aspectos que si bien han estado determinados por una mirada histórica, tomando acontecimientos y personajes; se tratan de realidades sociales.

\section{A modo de cierre}

Desde sus inicios, el cine en Colombia ha sido una pieza clave para presentar narraciones sobre la idiosincrasia de sus actores sociales, no solo como producto ficcional o de memoria histórica nacional sino como medio de comunicación preponderante en la construcción de imaginarios y representaciones sociales planteando una constante preocupación por el mundo simbólico de indeterminada noción de "colombianidad".

Tales imágenes y representaciones historiográficas de la infancia colombiana, han permitido una interpretación de la realidad cotidiana, como forma de conocimiento social especifica en una población poco estudiada en el campo fijando relaciones con los acontecimientos, objetos y comunicaciones que le conciernen en el trasegar como arte.

Los largometrajes creados en Colombia, en su mayoría realizados desde mediados hasta finales del siglo XX, han respondido a una "nueva" configuración que plantea la construcción de identidades y de formas apropiadas o no de ser sujetos.

De esta manera, la cinematografía colombiana plantea constantemente perspectivas para la construcción de la infancia, basada en procesos sociales reales y concretos donde las significaciones culturales abordadas incorporan al individuo (niño-niña) en la modificación del entorno inmediato en función de los tiempos de maduración biológicos, y las sensibilidades psico-emocionales que genera la vivencia de diferentes experiencias -en su mayoría- limites. ${ }^{25}$

25 De acuerdo con Ayala y Barragán (2005) una «experiencia límite», es aquel momento vivido, que al suceder colapsa la capacidad simbolizante del sujeto, altera su subjetividad y pone en acción otros registros, otras vías para responder, aun cuando estas dejan secuelas perjudiciales en el sujeto. 